\title{
ANÁLISE DO USO E COBERTURA DA TERRA DE TRÊS SUB-BACIAS HIDROGRÁFICAS - RIO GRANDE DO SUL/BRASIL
}

\author{
Aline Batista Ferreira ${ }^{1}$ \\ Waterloo Pereira Filho ${ }^{2}$ \\ Artigo recebido em $18 / 08$ /2009 e aceito em 05/11/2009
}

\section{RESUMO}

O artigo teve como objetivo realizar o levantamento do uso e ocupação da terra, por meio de classificação de imagens orbitais CBERS CCD 2, das sub-bacias do arroio Cadena e rios Vacacaí-Mirim e Ibicuí-Mirim, localizadas na mesorregião Centro Ocidental Rio-Grandense. As imagens foram processadas com o uso do software IDRISI 32, por classificação supervisionada que permitiu a identificação e quantificação das diferentes áreas de uso da terra (Área Urbana, Agricultura, Pastagens, Campos e Vegetação de pequeno porte, Corpos d'água e Florestamento). A metodologia adotada foi satisfatória, e os resultados encontrados forneceram dados de qualidade para o trabalho. Destacamos a importância das técnicas de geoprocessamento e sensoriamento remoto, para trabalhos em áreas urbanas, rurais e outras áreas afins.

Palavras-Chave: uso e ocupação da terra, sensoriamento remoto, imagens orbitais, classificação supervisionada.

\section{ANALYSIS OF USE AND LAND COVER OF THREE SUB-BASIN - RIO GRANDE DO SUL / BRAZIL}

\begin{abstract}
The article aimed to accomplish a survey about the use and occupation of land through a classification by orbital images of CCD CBERS 2, the watershed of the rivers Cadena Creek and Vacacaí-Mirim and Ibicuí-Mirim Rivers, located in central region of Rio Grande do Sul. The images were processed using the software IDRISI 32, through a supervised classification allowing the identification and quantification of different land-use areas (Urban Area, Agriculture, Pastures, fields and small size vegetation, water and Forestation). The methodology used was satisfactory, and the results found added quality for the paper. We emphasized the importance of the geoprocessing and remote sensing techniques, to work in urban, rural and other related areas.
\end{abstract}

Keywords: occupation and landuse, remote sensing, orbital images, supervised classification

\footnotetext{
${ }^{1}$ Doutoranda em Geografia, Universidade Federal de Uberlândia-PPGEO/UFU, Mestre em Geomática (UFSM), Bacharel em Geografia (UFU) e-mail: alineb_ferreira@yahoo.com.br

${ }^{2}$ Prof. Dr. do Depto. de Geociências,

Universidade Federal de Santa Maria -UFSM e-mail: waterloopf@gamil.com
} 


\section{1 - INTRODUÇÃO}

A expressão "uso da terra" pode ser entendida como sendo a forma pela qual o espaço está sendo ocupado pelo homem. $\mathrm{O}$ levantamento do uso da terra é de grande importância na medida em que os efeitos do uso desordenado causam deterioração no ambiente. Os processos de erosão intensos, as inundações, os assoreamentos desenfreados de reservatórios e cursos d'água são consequiências do mau uso do solo. A classificação do uso da terra numa dada região tornou-se um aspecto fundamental para a compreensão dos padrões de organização do espaço.

Algumas ferramentas importantes para se detectar e mapear estas mudanças são os produtos do sensoriamento remoto obtidos por plataformas orbitais e os sistemas de informações geográficas. O sensoriamento remoto tornou-se uma importante fonte de informações para monitorar os recursos naturais da Terra nas últimas décadas, devido à possibilidade de se adquirir dados sobre grandes extensões geográficas, e assim, possibilitando a partir desses monitoramentos uma melhor compreensão dos processos que ocorrem nestas áreas.

Nesta perspectiva, visou-se elaborar mapas temáticos de uso e ocupação da terra, com o intuito de realizar $\mathrm{o}$ levantamento do meio físico de três sub- bacias (Arroio Cadena, Rio Vacacaí-Mirim e Rio Ibicuí-Mirim).

Segundo Anderson et al. (2005), o mapeamento da cobertura vegetal e seu monitoramento mostram-se de extrema importância, e existe um esforço por parte da comunidade científica em melhorar a acurácia destes estudos. Estes trabalhos visam observar as mudanças devido a fatores naturais e antrópicos, buscar uma maior eficiência nas elaborações de planos de manejo de recursos naturais, assim como na análise da paisagem, delimitar as áreas prioritárias para a conservação, ou ainda realizar estudos que envolvem tópicos sobre mudanças globais, modelagens de ciclos biogeoquímicos, estimativas de emissão de carbono dentre outros.

O levantamento e mapeamento do uso e cobertura da terra de uma dada região ou município são importantes para mostrar a distribuição espacial das atividades de exploração e conservação na área (PEREIRA et al., 1994).

Para Pacheco (1998) o conhecimento atualizado da distribuição e da área ocupada pela agricultura, vegetação natural, áreas urbanas e edificadas, bem como informações sobre as proporções de suas mudanças, se tornam cada vez mais necessárias aos legisladores e planejadores. Desse modo, existe a necessidade de atualização constante dos registros de uso 
da terra, para que suas tendências possam ser analisadas.

O geoprocessamento pode ser definido como um conjunto de tecnologias para coleta, processamento, análise e disponibilização de informação com referência geográfica. Estas são compostas por soluções em hardware, software e peopleware, que, juntos, constituem poderosas ferramentas para tomada de decisão (ROSA; BRITO, 1996).

Dentre as geotecnologias, está o Sensoriamento Remoto por Satélites, sendo este um conjunto de processos e técnicas usado para medir propriedades eletromagnéticas de uma superfície ou de um objeto, sem que haja contato físico entre o objeto e o equipamento sensor. Em outras palavras, é a tecnologia que permite obter imagens e outros tipos de dados da superfície terrestre, por meio da captação do registro da energia refletida ou emitida pela superfície (MOREIRA, 2003).

Curran (1985), diz que o sensoriamento remoto ampliou a capacidade do homem em obter informações sobre os recursos naturais e o meio ambiente, colocando-se como mais uma ferramenta complementar para facilitar trabalhos temáticos e de levantamentos. Segundo Novo (1998), as principais vantagens que justificam os programas de sensoriamento remoto orbital são: estímulo às pesquisas multidisciplinares; informações de áreas de difícil acesso; universalização dos dados e das técnicas de tratamento e análise de dados digitais; facilidade do recobrimento de grandes áreas (visão sinóptica); cobertura repetitiva com mesma hora local; grande quantidade de dados pontuais, sobre uma mesma área; transferência de dados Satélite/Terra em tempo real; e o aspecto multiespectral, isto é, a capacidade dos sistemas sensores gerarem produtos em diferentes faixas espectrais, tornando possível o estudo e análise de elementos distintos, os quais são identificados em determinadas faixas do espectro.

Os satélites para estudos ambientais, vêm apresentando um notável desenvolvimento tecnológico, principalmente no que se refere à resolução espacial, espectral, radiométrica e temporal, possibilitando um acompanhamento periódico na análise da evolução do uso do solo e cobertura vegetal de determinada área. Cada sensor a bordo dos satélite apresentam distintas bandas que operam em diferentes faixas do espectro eletromagnético, conhecendo o comportamento espectral dos alvos na superfície terrestre é possível escolher as bandas mais adequadas para estudar os recursos naturais (SAUSEN, 1996).

Consoante com Diniz (1984), as etapas essenciais para a elaboração de mapas de utilização da terra são: aquisição 
de fotografias aéreas e/ou imagens de satélite; definição da escala do mapa; definição da chave de identificação, ou seja, elementos que permitam a identificação do tipo de utilização da terra nas fotografias aéreas e/ou imagens de satélite; elaboração da classificação em que devem ser colocados os eventos observados nas fotografias e/ou imagens. Classificação, em sensoriamento remoto, significa a associação de pontos de uma imagem a uma classe ou grupo, por exemplo, água, cultura, área urbana, entre outros. A classificação pode ser supervisionada e não-supervisionada. A classificação supervisionada é utilizada quando se tem algum conhecimento sobre as classes na imagem. Já a nãosupervisionada é utilizada quando não se tem informações sobre a área imageada, por exemplo, não se dispõe de dados prévios sobre o número de classes presentes. As classes são definidas no algoritmo de classificação (CRÓSTA, 1992).

Segundo Campbell (1996), a classificação supervisionada pode ser informalmente definida como o processo no qual amostras de identidade conhecida são utilizadas para classificar pixels de identidade desconhecida. Neste processo, um analista identifica na imagem as classes de informação de seu interesse e separa regiões que melhor representem estas Ferreira, A. B. e Filho, W. P. classes. Dentro destas regiões ele separa áreas de treinamento que contêm os pixels que serão usados como representantes da classe. A partir destes pixels são extraídas determinadas características das classes, que serão usadas para a classificação dos demais pixels.

Segundo Rosa et al (2004), bacia hidrográfica é uma área topograficamente definida pela drenagem de um canal fluvial ou por um sistema de canais fluviais conectados, de tal forma que toda água drenada nesse espaço tenha uma única saída. Cada bacia hidrográfica pode ser subdividida em bacias menores, o que significa dizer que uma bacia hidrográfica é formada por um conjunto de pequenas bacias.

De acordo com Tucci (1997), é uma área de captação natural da água da precipitação que faz convergir os escoamentos para um único ponto de saída, seu exutório.

Segundo Rocha (1997), bacia hidrográfica é a área que drena as águas de chuvas por ravinas, canais e tributários para um curso principal com vazão efluente convergindo para uma única saída e desaguando diretamente no mar ou em um grande lago. As sub-bacias hidrográficas deságuam diretamente em outro rio. A micro-bacia hidrográfica é definida como a área de formação natural, drenada por um curso d'água e seus 
afluentes. Em termos gerais, a micro-bacia é uma sub-bacia hidrográfica de área reduzida.

As bacias hidrográficas possuem em sua rede de drenagem uma hierarquização, sendo que a água sofre escoamento do ponto mais alto para o mais baixo. A drenagem significa o traçado produzido pelas águas fluviais modelando a topografia (GUERRA et al, 2003). Estes traçados formam os padrões de drenagem em cartas ou em fotografias áreas. Contudo Christofoletti (1980), afirma que a drenagem fluvial e composta por um conjunto de canais de escoamento interrelacionados que formam a bacia de drenagem, sendo definida como a área drenada por um rio ou sistema fluvial.

A inclinação das vertentes e um fator importante nos processos erosivos, quando associados ao uso da terra e cobertura vegetal nas grandes áreas expostas (como pastagem ou solo exposto), sendo que na maioria das vezes não se encontram curvas de nível ou qualquer tipo de cobertura vegetal e o escoamento superficial se torna mais rápido $\mathrm{e}$, consequentemente, a lixiviação do solo torna-se frequente.

\section{2- IOCALIZAÇÃO CARACTERIZAÇÃO DAS ÁREAS}

$\mathbf{E}$

As três sub-bacias estão inseridas na mesorregião Centro Ocidental RioFerreira, A. B. e Filho, W. P.
Grandense. A sub-bacia do arroio Cadena está localizada nas coordenadas $29,65^{\circ}$ e $29,73^{\circ}$ de latitude sul e $53,80^{\circ}$ e $53,86^{\circ}$ de longitude oeste de Greenwich. A SB do rio Vacacaí-Mirim nas coordenadas $29,61^{\circ}$ e $29,70^{\circ}$ de latitude sul e $53,71^{\circ}$ e $53,83^{\circ}$ de longitude oeste de Greenwich, ambas inseridas no município de Santa Maria-RS, e possuem uma área de cerca de $4.883,40$ ha e $6.367,39$ ha, respectivamente. Já a sub-bacia do rio Ibicuí-Mirim está localizado entre os municípios de Santa Maria, Itaara e São Martinho da Serra-RS, nas coordenadas $29,45^{\circ}$ e $29,60^{\circ}$ de latitude sul e $53,70^{\circ}$ e $53,85^{\circ}$ de longitude oeste, possuindo uma área de aproximadamente 15.955,28 ha.

O Rio Grande do Sul apresenta quatro grandes compartimentos geomorfológicos: planalto, depressão central, escudo sul-rio-grandense e planície costeira. Neste contexto, as áreas em estudo, localizadas no centro do estado, ocupam áreas de planalto e da depressão central (CASTILLERO, 1984).

Quanto à pedologia, as sub-bacias estão inseridas em três unidades de mapeamento que são: Unidade de Mapeamento São Pedro, Unidade de Mapeamento Santa Maria e Unidade de Mapeamento Venda Grande (CASAGRANDE, 2004).

A vegetação da região compreende basicamente por formações florestais - 
Floresta Subtropical, latifoliada de espécies semicaducifólias, encontrada no rebordo do planalto, ao longo dos vales, em regiões de grande declividade, compreendendo formações montanas e submontanas; formações campestres - campos cobertos por gramináceas contínuas, entremeadas de subarbustos isolados e formações especiais correspondentes às matas de galeria e vegetação ribeirinha (RUHOFF et al, 2003).

A região está ainda sujeita, no outono e no inverno, ao fenômeno do "veranico", que consiste de uma sucessão de dias com temperaturas anormalmente elevadas para a estação. De acordo com o sistema de classificação de Köppen, o clima é o subtropical "Cfa", com temperatura média anual de $19,3^{\circ} \mathrm{C}$; a média das temperaturas máximas do mês mais quente (janeiro) é de $31,5^{\circ} \mathrm{C}$ e do mês mais frio (julho) atinge os $9,3^{\circ} \mathrm{C}$; a temperatura mínima absoluta é geralmente de $0^{\circ} \mathrm{C}$, e a máxima absoluta é de $35^{\circ} \mathrm{C}$ (ISAIA, 1992).

\section{3 - MATERIAIS E PROCEDIMENTOS METODOLÓGICOS}

\subsection{Materiais}

Documentos e Softwares

- Folhas topográficas de Camobi, Santa Maria, Arroio Guassupi e Val de Serra fornecidas pelo Exército na escala de 1:50.000.
- Imagens do sensor CBERS-CCD, de 26/10/2006, no formato digital, composição 3B4R2G.

- IDRISI 32 - é um sistema de informação geográfica que serve para processamento de imagens, desenvolvido pela Graduate School of Geography da Clark Universit, baseado no formato raster de representação de dados, foi desenvolvido para microcomputadores. Sendo utilizado na funcionalidade analítica raster e cobre todo o espectro de necessidades de SIG e de sensoriamento remoto, desde consulta a banco de dados e modelagem espacial até realce e classificação de imagens (EASTAM, 1998).

\subsection{Procedimentos metodológicos}

Para alcançar os objetivos propostos na pesquisa e seu desenvolvimento utilizaram-se técnicas de geoprocessamento e sensoriamento remoto, bem como campanhas a campo.

\section{Uso da Terra}

O mapa de uso foi elaborado no Idrisi 32, utilizando a imagem CBERS 2CCD. Primeiramente, fez-se o georreferenciamento das bandas, com o 
comando "Resample" pertencente ao módulo "Reformat". georreferenciamento da imagem CBERS 2-CCD foi executado através da identificação de pontos de controle na imagem digital, visualizada no monitor do computador, e posterior localização dos mesmos nas cartas topográficas, tendo sido selecionados 20 pontos de controle. Após a seleção dos pontos de controle nas cartas topográficas e nas imagens, os mesmos foram transferidos para um banco de dados no software de geoprocessamento IDRISI 32, etapa que compreendeu a correção geométrica através de um modelo linear, com a utilização de um polinômio de $1^{\circ}$ grau, e técnica de reamostragem por vizinho mais próximo. A correção geométrica da imagem consistiu na associação das coordenadas da imagem (linha e coluna), com as coordenadas geográficas (latitude e longitude) adquiridas através de mapas topográficos na escala 1:50.000 do IBGE.

Após este procedimento, foi realizada a conversão dos limites de cada sub-bacia de vetor para raster, para assim realizar o recorte das bandas com os limites por meio do comando "Overlay" pertencente ao módulo "GIS Analysis/Database Query", em seguida foi realizada a composição colorida de cada sub-bacia utilizando-se o comando
"Composite" do módulo "Image Processing/Enhancement".

Para a elaboração dos mapas de Uso e Cobertura da Terra, foi realizada a classificação supervisionada da imagem. Foram coletadas, para cada classe de uso áreas de treinamento, sendo que para cada sub-bacia foi criado um arquivo vetorial e para cada classe de uso foram atribuídos identificadores. A digitalização das áreas ocorreu por meio do comando "Digitize". Após o reconhecimento de todas as classes, foram criados os arquivos de assinaturas pelo comando "Makesig" do módulo "Image Processing/Signature Development". Com o comando "Maxlike" pertencendo ao módulo "Image Processing/Hard classifiers", foi realizada a classificação por máxima verossimilhança, sendo assim, elaborado o pré-mapa. Os trabalhos de campo serviram de suporte para a conferência dos atributos espaciais e a elaboração do mapa final de Uso e Cobertura da Terra.

\section{Morfometria}

Os estudos morfométricos são instrumentos básicos para o desenvolvimento de planos de gestão que visem à utilização racional do meio ambiente e a compreensão dos processos naturais atuantes neste meio. As equações abaixo foram utilizadas para os cálculos 1densidade de drenagem, 2- declividade 
média da bacia, 3-coeficiente de Cadena e dos rios Vacacaí-Mirim e Ibicuírugosidade das sub-bacias do arroio Mirim:

Equação 1 - Densidade de drenagem:

$$
\mathrm{D} d=\frac{L t}{\mathrm{~A}}
$$

Equação 2 - Declividade média da sub-bacia:

$$
\mathrm{H}=\frac{(\mathrm{Cn} * \mathrm{~h})}{\mathrm{A}} * 100
$$

Equação 3 - Coeficiente de rugosidade:

$$
\mathrm{RN}=\mathrm{D} d^{*} \mathrm{H}
$$

Em que:

Lt é a soma dos comprimentos dos canais (em Km)

Cn é a soma, em Km, dos comprimentos de todas as curvas de nível;

h é a eqüidistância, em Km, entre as curvas de nível

A é a área da sub-bacia em ha.

\section{4 - ANÁLISE DOS RESULTADOS}

Como resultados foram gerados mapas de uso e cobertura da terra e índice de vegetação, para avaliar o grau de deterioração das sub-bacias (SB). Como observa-se na Figura 2, e na Tabela 1, a sub-bacia do arroio Cadena é a mais urbanizada abrangendo $62,40 \%$ de sua área. Na área urbana o arroio se encontra bastante poluído, pois são despejados dejetos e lixos (Figura 1 (a)) em quase toda a sua extensão, não se respeitando os limites da área de preservação permanente Ferreira, A. B. e Filho, W. P.
(APP). Nos locais onde o Cadena não foi canalizado, existem construções nas margens (Figura 1(b)), as quais também são ocupadas por uma pequena percentagem de vegetação (Figura 1(c)), nas áreas de rebordo e depressão são encontradas áreas de florestas, campos e vegetação de pequeno porte (Figura 1(d)), que ocupam pouco mais de $16 \%$ da área total da sub-bacia.

A sub-bacia do arroio Cadena não possui altas declividades, por isso a ocupação tão intensa por atividades antrópicas. 


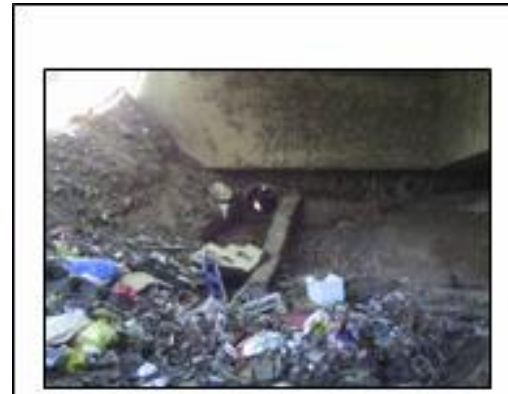

(a) Lixo e esgoto

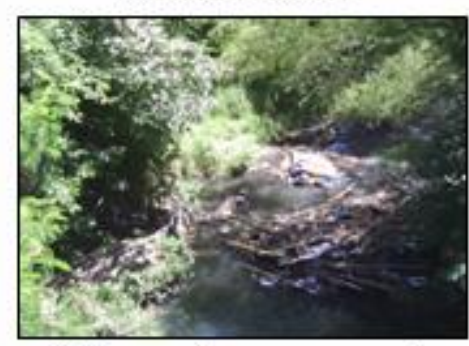

(c) Vegetação as margens do Cadena

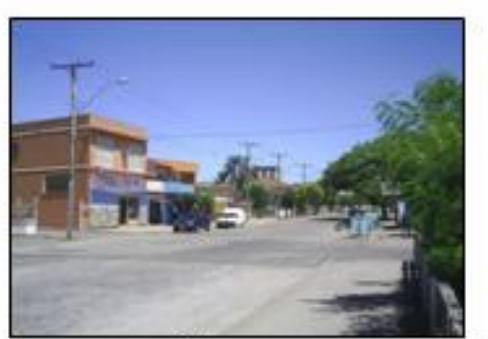

(b) Area Urbana

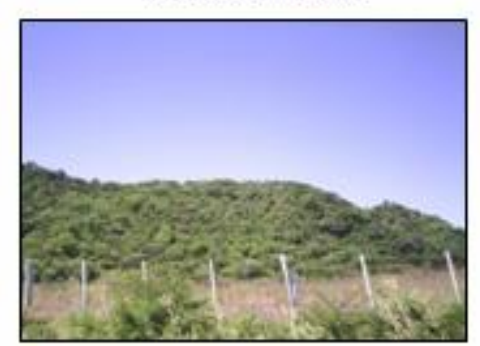

(d) Campo e Floresta

Figura 1 - Tipos de uso na sub-bacia do Arroio Cadena

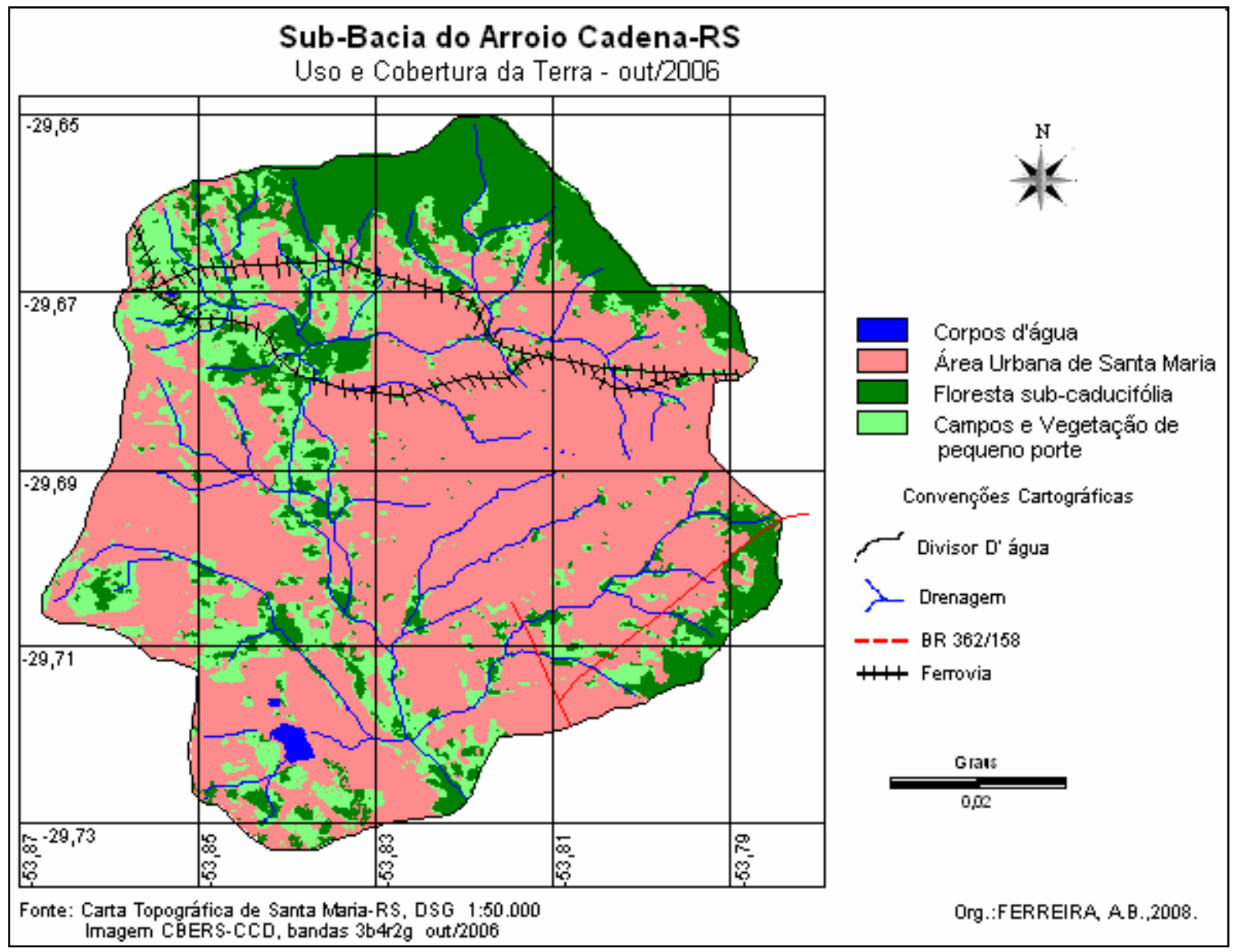

Figura 2 - Uso e Cobertura da Terra da Sub-bacia do Arroio Cadena 
A sub-bacia do Rio Vacacaí-Mirim (Figura 4), possui cerca de $22,44 \%$ de sua área inserida na área urbana de Santa Maria. E cerca de $55 \%$ da área é ocupada por florestas e campos, como pode ser observado na Tabela 1.

O leito do rio se encontra bastante deteriorado, devido à prática inadequada da agricultura e o crescimento urbano de Santa Maria (Figura 3), o que leva a contaminação por meio de esgoto e lixo jogados na água, onde há urbanização.

O uso inadequado de fertilizantes contribui também para a poluição da água do rio. O nível do rio também sofre com a prática da cultura, principalmente de arroz, pois ao longo de seu leito são encontradas bombas para a captação de água para a irrigação, nos meses de verão, época em que o volume de água se encontra baixo devido às estiagens. Esse uso intensivo das terras nas margens do rio Vacacaí-Mirim, além de ocasionar erosão e assoreamento, também contribui para a deposição de sólidos no fundo do vale.

A sub-bacia possui uma declividade relativamente alta a montante, fato pelo qual ainda se tem grandes áreas preservadas. Nas áreas de baixa declividade são encontradas áreas de pasto e agricultura, que ocupam pouco mais de $21 \%$ (Tabela 1) da área total da sub-bacia. A SB do rio Vacacaí-Mirim, também é responsável pelo abastecimento de água equivalente a $40 \%$ dos domicílios comerciais e residenciais da cidade de Santa Maria, por meio da Barragem do DNOS. 


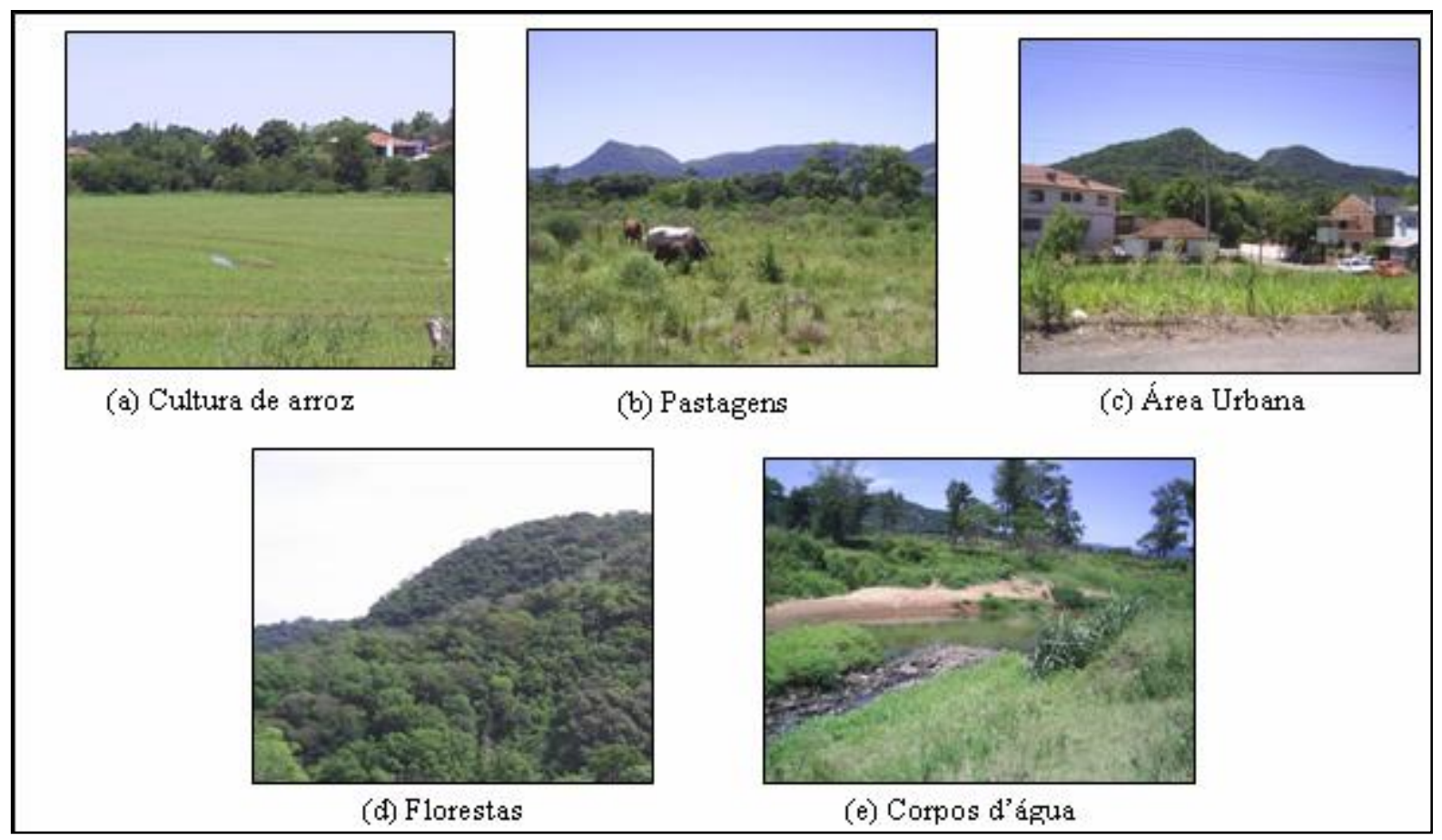

Figura 3 - Tipos de uso na sub-bacia do Rio Vacacaí-Mirim

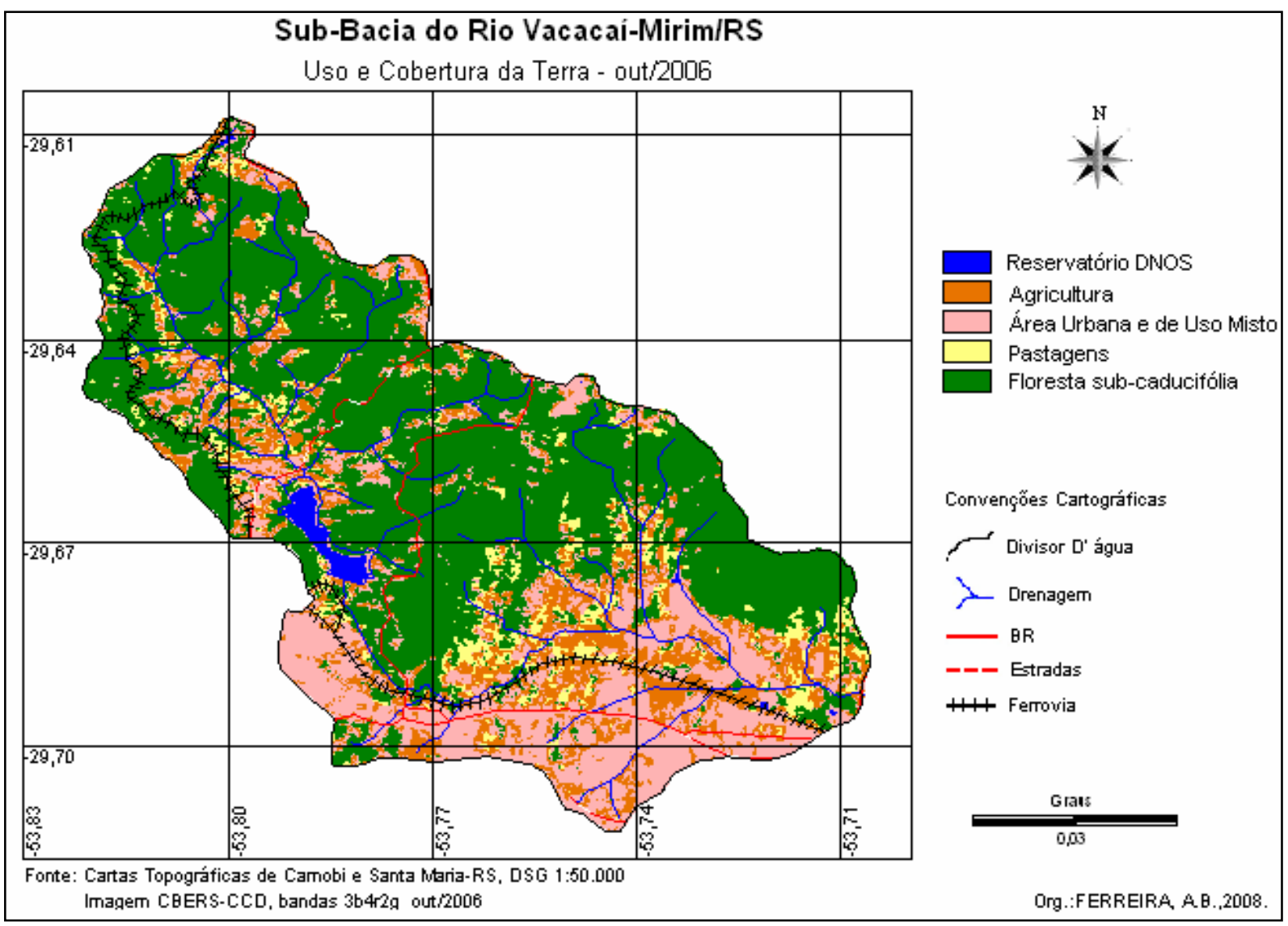

Figura 4 - Uso e Cobertura da Terra da Sub-bacia do Rio Vacacaí-Mirim

As áreas agrícolas ocupam cerca de 29,03\% (Tabela 1) da área total da sub- bacia do rio Ibicuí-Mirim (Figura 6 e Tabela 1), e predominam entorno do 
reservatório, o qual deveria estar protegido por áreas de vegetação.

As áreas agrícolas passam por modificações durante o ano, dentre essas se encontra a fase em que o solo se encontra exposto, o qual sofre remoção, levando ao depósito de sólidos no fundo do vale nas proximidades das áreas ocupadas por práticas agrícolas.

As áreas de florestas que representam aproximadamente $35,41 \%$ (Tabela 1) da área da sub-bacia se encontram mais na parte sul, ou seja, a

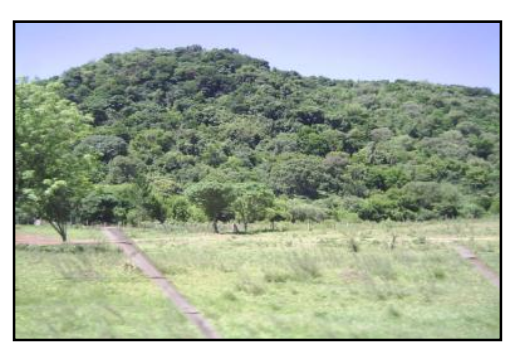

(a) Pasto e floresta

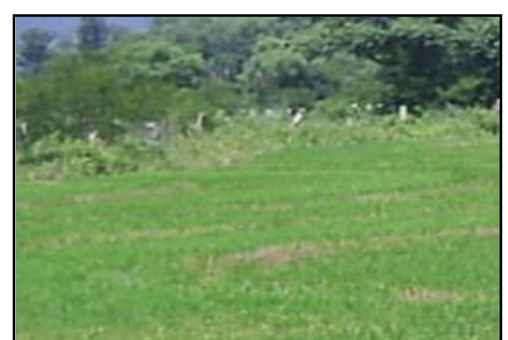

(c) Agricultura jusante, fato este ocasionado pelas altas declividades no local, o qual impede o manejo agrícola.

Os principais usos identificados na sub-bacia do rio Ibicuí-Mirim podem ser visualizados na Figura 5.

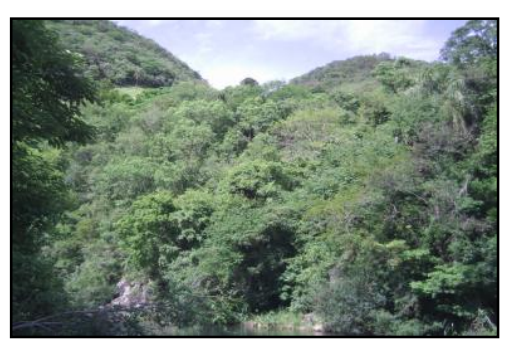

(b) Floresta

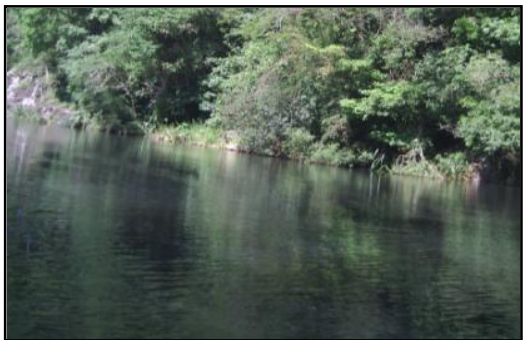

(d) Rio Ibicuí-Mirim

Figura 5 - Tipos de uso na sub-bacia do Rio Ibicuí-Mirim 


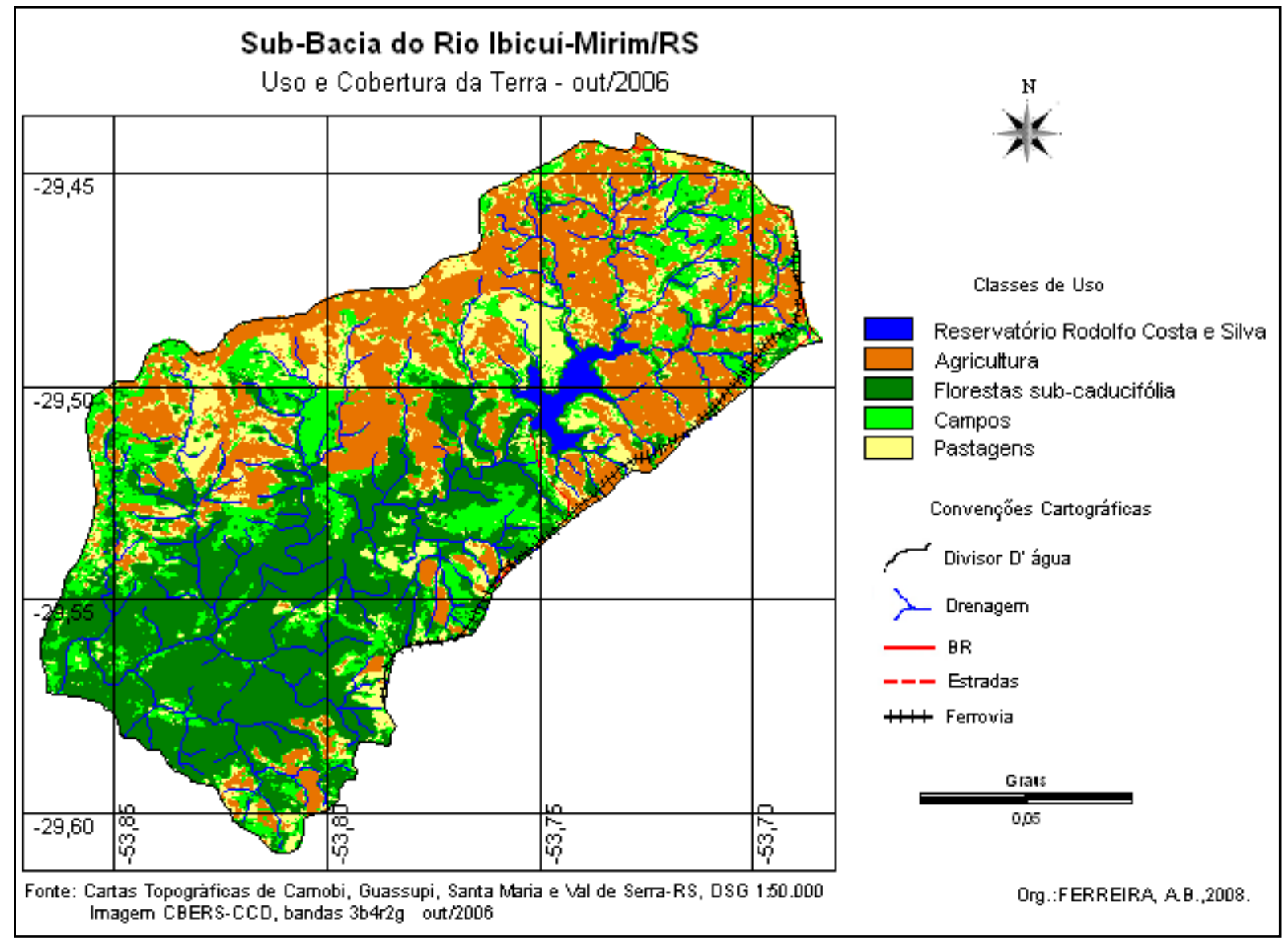

Figura 6 - Uso e Cobertura da Terra da Sub-bacia do Rio Ibicuí-Mirim

Tabela 1 - Área ocupada pelas diferentes categorias de uso da terra, 2006

\begin{tabular}{|c|c|c|c|c|c|c|c|c|c|}
\hline \multirow{3}{*}{ Categorias } & \multirow{2}{*}{\multicolumn{3}{|c|}{$\begin{array}{c}\text { Cadena } \\
\text { Área }\end{array}$}} & \multirow{2}{*}{\multicolumn{3}{|c|}{$\begin{array}{c}\text { Vacacaí-Mirim } \\
\text { Área }\end{array}$}} & \multirow{2}{*}{\multicolumn{3}{|c|}{$\frac{\text { Ibicuí-Mirim }}{\text { Área }}$}} \\
\hline & & & & & & & & & \\
\hline & $h a$ & $m^{2}$ & $\%$ & $h a$ & $m^{2}{ }^{K}$ & $\%$ & $h a$ & $m^{2}{ }^{K}$ & $\%$ \\
\hline $\begin{array}{l}\text { Corpos } \\
\text { d'água }\end{array}$ & 17,12 & 0,1712 & 0,30 & 60,04 & 0,6004 & 0,94 & 244,00 & 2,4400 & 1,53 \\
\hline Agricultura & & - & & 984,52 & 9,8452 & 15,47 & 4632,56 & 46,3256 & 29,03 \\
\hline $\begin{array}{c}\text { Área Urbana } \\
\text { e } \\
\text { Uso Misto }\end{array}$ & 3046,76 & 30,4676 & 62,40 & 1429,08 & 14,2908 & 22,44 & - & - & - \\
\hline Pastagens & - & - & - & 385,64 & 3,8564 & 6,06 & 2426,36 & 24,2636 & 15,21 \\
\hline $\begin{array}{c}\text { Florestas } \\
\text { sub- } \\
\text { caducifólia }\end{array}$ & 950,92 & 9,5092 & 19,50 & 3507,72 & 35,0772 & 55,09 & 5649,24 & 56,4924 & 35,41 \\
\hline $\begin{array}{c}\text { Campos e } \\
\text { Vegetação } \\
\text { de pequeno } \\
\text { porte }\end{array}$ & 868,60 & 8,6860 & 17,80 & - & - & - & 3003,12 & 30,0312 & 18,82 \\
\hline Total & 4883,40 & 48,8640 & 100 & 6367,39 & 63,6739 & 100 & 15955,28 & 159,5528 & 100 \\
\hline
\end{tabular}

Ferreira, A. B. e Filho, W. P. 
Como se pode observar na Figura 7 (b), as maiores densidades de drenagens são encontradas nas SB do rio Ibicuí$\operatorname{Mirim}(0,01566 \mathrm{~km} / \mathrm{ha})$ e do arroio Cadena $(0,01555 \mathrm{~km} / \mathrm{ha})$, por apresentar maior densidade de drenagem e conseqüentemente menor transmissibilidade (medida da permeabilidade do terreno), possui maior suscetibilidade a erosão e maior potencial dispersor da contaminação nas águas superficiais, no caso da sub-bacia do arroio Cadena, como já foi mencionado este fato ocorre por está se localizar na área urbana de Santa Maria.

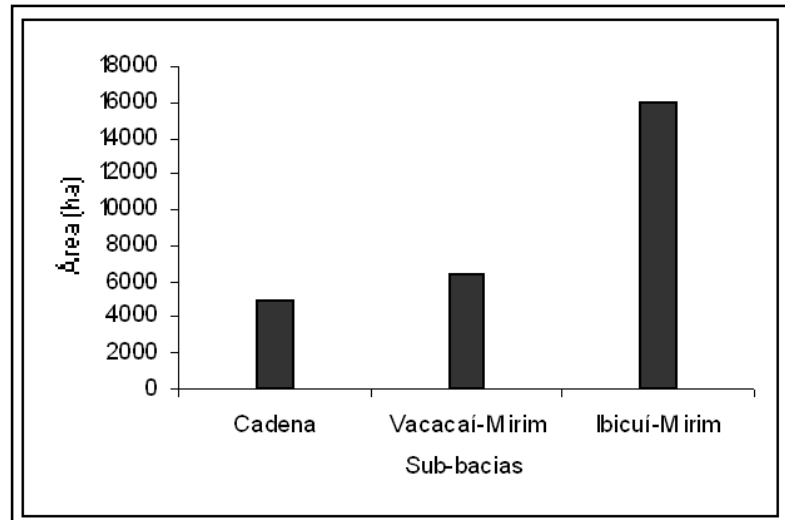

(a)

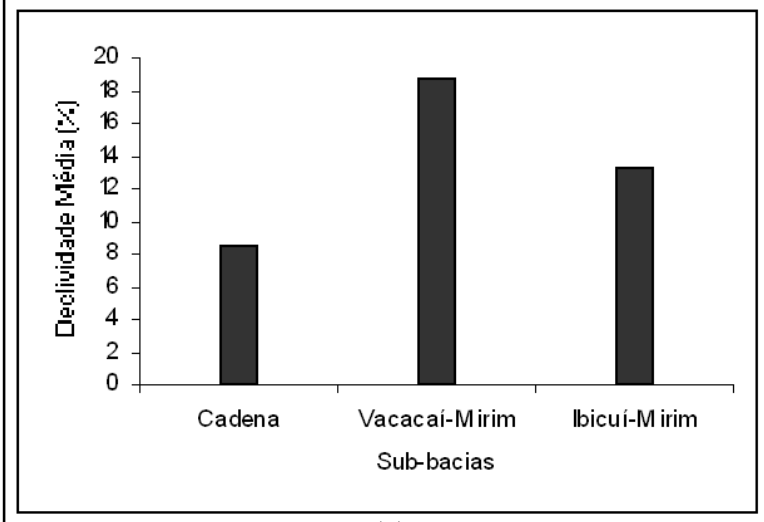

(c)
Quanto à declividade média, na SB do arroio Cadena está é inferior a $10 \%$ $(8,73 \%)$, caracterizando um relevo plano a ondulado (Figura 7 (c)), o que propiciou a intensa ocupação urbana nessa área.

A SB do rio Vacacaí-Mirim por possuir declividade média relativamente alta $(18,70 \%)$ e um elevado coeficiente de rugosidade $(25,22)$, se apresenta mais susceptível aos processos erosivos.

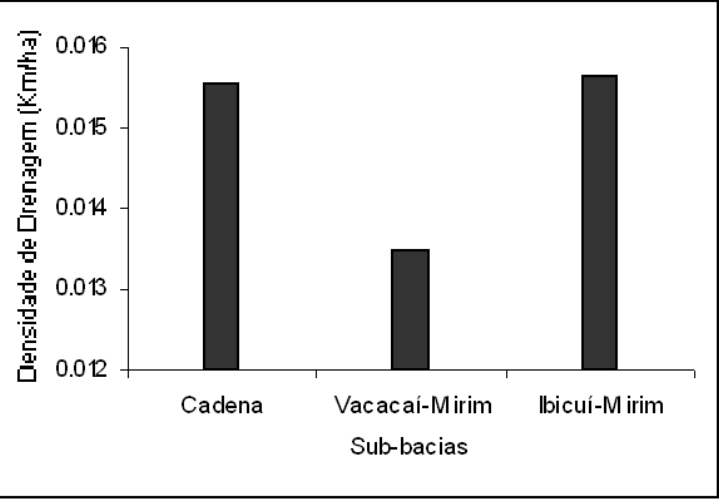

(b)

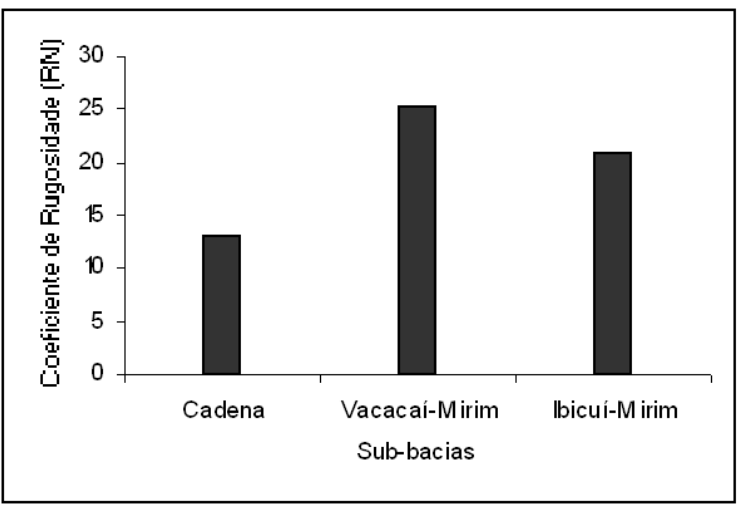

(d)

Figura 7 - Informações espaciais e morfométricas das Sub-bacias 


\section{5 - CONCLUSÃO}

Os resultados apresentados na forma de mapas temáticos uso da terra e índice de vegetação permitiram o conhecimento do meio físico das três sub-bacias analisadas, bem como dos processos dinâmicos que podem contribuir para um melhor ordenamento do uso da terra. Como observado nos mapas de uso da terra, as SB do arroio Cadena e do rio VacacaíMirim, apresentam poucas áreas florestadas as suas margens principalmente nos pontos de coleta.

É importante salientar que o Geoprocessamento e o SR permitiram coletar e analisar a informação muito rapidamente. Logo, estas tecnologias podem ser vistas como integradoras que auxiliam os geógrafos na analise de sistemas naturais e sociais, servindo de instrumento eficiente para todas as áreas do conhecimento que fazem uso de mapas, possibilitando, então, integrar em uma única base de dados informações representando vários aspectos do estudo de uma região e gerando novos tipos de informações.

O processo de classificação supervisionada apresenta vantagens e desvantagens. As principais vantagens são: a) $\mathrm{O}$ analista tem maior controle sobre $\mathrm{o}$ processo (determina o número e o tipo de classes, as regiões de amostragem e o número de amostras). Esta característica é importante principalmente quando a classificação visa a um objetivo específico; b) a classificação supervisionada é demarcada pelas classes pré-definidas pelo analista, desta forma, não é necessário concatenar a imagem classificada com as classes de interesse; e c) o analista tem condições de identificar possíveis imprecisões graves pela análise das áreas de treinamento.

As principais desvantagens são: a) $\mathrm{O}$ analista impõe uma determinada estrutura de classificação aos dados, através da definição prévia das classes de informação. Estas classes podem não corresponder às classes reais existentes na cena imageada, ou não serem separáveis no espaço ndimensional; e b) As áreas de treinamento selecionadas podem não apresentar todas as características das classes que representam. Esta característica pode ter muita influência, principalmente quando a área a ser classificada é grande, complexa ou inacessível (CAMPBELL, 1996).

O estudo do meio físico, especialmente ao nível de bacias hidrográficas, ganha relevância significativa no planejamento da ocupação de novas áreas, ou na reestruturação de áreas antigas, considerando as demandas ambientais naturais da área e seus limites de utilização.

Os resultados encontrados permitiram concluir que a metodologia utilizada para o 
levantamento do meio físico foi satisfatória, atendendo à primeira proposta da pesquisa.

\section{REFERÊNCIAS BIBLIOGRÁFICAS}

ANDERSON, L. O et al. Utilização de dados multitemporais do sensor MODIS para o mapeamento da cobertura e uso da terra. In: SIMPÓSIO BRASILEIRO DE SENSORIAMENTO REMOTO, 12., 2005, Goiânia, Anais..., Goiânia, 2005. p. 34433450.

CAMPBELL, J. B. Introduction to remote sensing. New York: Ed. The Guilford Press, 1996. 622 p.

CASAGRANDE, L. Avaliação do parâmetro de propagação de sedimentos do modelo de williams (1975) na bacia do rio vacacaí-mirim com o auxílio de técnicas de geoprocessamento. 2004. 242 p. Dissertação (Mestrado Engenharia Cívil) Universidade Federal de Santa Maria (UFSM), Santa Maria.

CASTILlERO, A. C. Uso da terra por fotografias aéreas no município de Santa Maria, RS.1984. 47f. Monografia (Especialização em Imagens Orbitais) Universidade Federal de Santa Maria. 1984.

CHRISTOFOLETTI, A. Geomorfologia. São Paulo: Ed. Edgar Blücher, 2. ed., 1980, $188 \mathrm{p}$.

CRÓSTA, A. P. Processamento digital de imagens de sensoriamento remoto. Campinas: Ed. IG/Unicamp,1992. 170 p.

CURRAN, P. J. Principles of remote sensing. London: Ed. Longman, 1985, 282 p.

DINIZ, F. J.A. Geografia da Agricultura. 2. ed. São Paulo: Ed. DIFEL, 1984. 278 p. DE FELIPPO, R. et al. As alterações na qualidade da água durante o enchimento do reservatório de UHE Serra da Mesa-GO. In: HENRY, R. Ecologia de reservatórios: estrurura, função $e$ aspectos sociais. Botucatu: FUNDIBIO, 1999. p. 321-346.

EASTMAN, J. R. Idrisi for Windows Manual do usuário: introdução e exercícios tutoriais. Editores da versão em português, Heinrich Hasenack; Eliseu Weber. Porto Alegre, UFRGS Centro de Recursos Idrisi, 1998. 240 p.

GUERRA, A. J. T.; BOTELHO, R. G. M Encostas e questão ambiental. In: CUNHA, S. B. da; GUERRA, A. J. T. (Orgs.). A questão ambiental: diferentes abordagens. Rio de Janeiro, Ed. Bertrand Brasil, 2003, p.191-218.

ISAIA. T. Planejamento de uso da terra para o município de Santa Maria- RS, através do diagnóstico físico conservacionista das microbacias hidrográficas. Santa Maria. 1992. 60 p.

LARENTIS, D. G. Modelagem Matemática da Qualidade da Água em Grandes Bacias: Sistema TaquariANTAS-RS. 2004, 177 p. Dissertação (Mestrado em Engenharia). Instituto de Pesquisas Hidráulicas da Universidade Federal do Rio Grande do Sul (IPH). Rio Grande do Sul.

MOREIRA, Maurício Alves. Fundamentos do Sensoriamento Remoto e Metodologias de Aplicação. São José dos Campos/SP: Instituto Nacional de Pesquisas Espaciais (INPE), 2003, 304 p.

NOVO, E. M. L. M. Sensoriamento remoto: princípios e aplicações. 2.ed -3 . Reimpressão. São Paulo: Edgard Blucher Ltda, 1998. 308 p.

PACHECO, A. P., RIBAS, N. S., Sensoriamento Remoto aplicado ao Uso da Terra. GEODÉSIA online. Revista da 
Comissão Brasileira de Geodésia. Recife, v. 4, 1998.

PEREIRA NETO, O. C. Técnicas de geoprocessamento aplicadas ao estudo da adequação do uso do solo em bacias hidrográficas. 1994, 124 p. Dissertação (Mestrado em Sensoriamento Remoto). Instituto de Pesquisas Espaciais (INPE). São José dos Campos.

ROCHA, J. S. M. Manual de projetos ambientais. Santa Maria: Imprensa Universitária, 1997. p. 71-136.

ROSA, R et al. Elaboração de uma base cartográfica e criação de um banco de dados georreferenciados da bacia do Rio Araguari - MG. In: LIMA, S. C.; SANTOS, R. J. (Org.) Gestão ambiental da bacia do Rio Araguari: rumo ao desenvolvimento sustentável.

Universidade Federal de Uberlândia. Instituto de Geografia. Brasília: CNPq. p. $69-87,2004$.

ROSA, R.; BRITO, J. L. Introdução ao Geoprocessamento: Sistema de Informação Geográfica. Uberlândia, UFU, 1996.

RUHOFF, A. L. et al. Mapeamentos de Uso da Terra e Ocupação do Espaço Geográfico em Santa Maria, RS. Curitiba, n. 7, p. 87-94, 2003. Ed. UFPR. Disponível em <http://coralx.ufsm.br/mundogeo/Links/Pu blicacao_arquivos/RAE-2004-22.pdf> acesso em 22/08/2007.

SAUSEN, T. M. Introdução ao sensoriamento remoto, Caderno de atividades XI CISR. Instituto Nacional de Pesquisas Espaciais (INPE). São José dos Campos, 1996.

SELLERS JR, T. Plywood and Adhesive Technology. New York: Marcel Dekker, 1985. $661 \mathrm{p}$.
TUCCI, C. E. M. Plano Diretor de Drenagem Urbana: Princípios e Concepção. Revista Brasileira de Recursos Hídricos, v. 2, n. 2, p. 5-12, julho/dezembro1997. 